\title{
Modernização da Agricultura em Moçambique: determinantes da renda agrícola
}

\author{
Carlos E. Guanziroli e Tomás Guanziroli²
}

Resumo: O objetivo deste trabalho é verificar até que ponto as tecnologias oriundas da revolução verde foram efetivamente adotadas na África Subsaariana e, nos casos em que foram adotadas, se tiveram sucesso em melhorar a renda e a produtividade da agricultura. Para este fim, o trabalho faz primeiramente um breve resumo do estado das artes da revolução verde na África, mostrando quais países avançaram mais e como se correlaciona a utilização de fertilizantes químicos com os aumentos de produtividade. Faz-se também uma discussão sobre as características do processo de intensificação num caso em particular, o de Moçambique. Finalmente, com base nos microdados do Tratado de Inquérito Agrícola (TIA), se testa um modelo econométrico de MQO que visa avaliar os determinantes da renda agrícola e, em particular, do uso de fertilizantes químicos.

Palavras-chaves: produtividade agrícola, agricultores emergentes, fertilizantes.

Abstract: The aim of this study is to verify to what extent the technologies coming from the green revolution were effectively adopted in sub-Saharan Africa, and, in cases in which they were adopted, if succeeded in improving agricultural productivity and income. To this end, the work makes first a brief summary of the State of the arts of the green revolution in Africa, showing which countries have advanced more and how the use of chemical fertilizers correlates with productivity increases. The article also discusses the characteristics of the intensification process in a particular case, of Mozambique. Finally, based on micro data of the Agricultural Survey (TIA), an econometric model MQO is tested, aiming to assess the determinants of agricultural income, and, in particular, the use of chemical fertilizers.

Key-words: agricultural yield, emergent farmers, fertilizers.

Classificação JEL: Q14.

http://dx.doi.org/10.1590/1234-56781806-94790053s01009

1. Doutor em Economia pela University College London e Professor Associado IV da Faculdade de Economia / Universidade Federal Fluminense. E-mail: carlos.guanzi@gmail.com

2. Economista e Mestre em Economia pela Pontifícia Universidade Católica de Rio de Janeiro. PUC-RJ. E-mail: tomguanzi@hotmail.com 


\section{Introdução}

Antes da revolução verde, os países desenvolvidos promoviam a adoção do modelo "difussionista", que se baseava principalmente no uso de mecanização de grande escala combinado com outras técnicas agrícolas.

Este modelo sugeria que os agricultores camponeses dos países pobres seriam incapazes de adotar tecnologias modernas e que, portanto, iriam migrar para as cidades para se integrar no processo de industrialização que inevitavelmente ocorreria em todos os países, conforme e versão rostowiana da história (ROSTOW, 1960).

William Arthur Lewis contribuiu decisivamente nesta linha de pensamento ao mostrar que os agricultores pobres dos países subdesenvolvidos que tinham "produtividade do trabalho nula ou até negativa" (LEWIS, 1964), acabariam abandonando a agricultura e migrando as cidades. Este contingente caracterizado por ele como "oferta ilimitada de mão de obra", contribuiria com o desenvolvimento industrial, dados os baixos salários que os migrantes obteriam nos empregos nas cidades.

O modelo difusionista antes citado permitiria a substituição do trabalhador manual por máquinas e, dessa forma, facilitaria o processo de migração as cidades.

Outros autores criticaram este modelo, como sendo "armadilha de nível baixo" (JORGENSON, 1961), porque o abandono persistente dos cam- poneses da agricultura diminuiria a oferta de alimentos, cujos preços aumentariam tendencialmente, criando, consequentemente, problemas para o processo de industrialização -via aumento nos preços de alimentos.

Mas foi Shultz (1961) no seu afamado livro "Transforming Traditional Agriculture" quem dera as bases teóricas para a mudança de pensamento, que posteriormente embasara a revolução verde. Shultz critica a hipótese central do modelo difusionista de que os pequenos produtores seriam incapazes de adotar tecnologias modernas por serem "atrasados, arcaicos ou irracionais".

Segundo Shultz, os produtores rurais dos países pobres eram "pobres, porém racionais", ou seja, são alocativamente eficientes e racionais e, senão aplicam técnicas modernas, não seria por falta de sabedoria ou por atraso mental, mas por falta de recursos financeiros e condições estruturais. $\mathrm{Ou}$ seja, por falta de condições sociais e econômicas para sua adoção.

A Revolução Verde em todos os países onde aconteceu muda o foco em relação ao modelo difusionista: ao invés de promover a mecanização de grande escala - que expulsa os trabalhadores do campo sem garantia de emprego nas cidadesincentiva, via crédito subsidiado, o uso de técnicas modernas de cultivo, em particular a aplicação de fertilizantes químicos, sementes híbridas e defensivos (pesticidas, herbicidas e fungicidas) aliado ao uso de irrigação em pequena escala. 
Estas tecnologias são neutras em escala, podendo ser adotadas por um grupo abrangente de produtores (basta mudar o patamar no uso dos insumos na medida em que se aumenta a escala). Fertilizantes e sementes são divisíveis, ao contrário de tratores e colheitadeiras, que exigem alta escala para serem eficientes e economicamente viáveis.

$\mathrm{O}$ uso de insumos agrícolas tornou-se fundamental na revolução verde da agricultura moderna dos países desenvolvidos que posteriormente, nas décadas de 1960 e 1970, se espalhou pela Ásia e América Latina.São amplamente conhecidos os efeitos sobre a produtividade agrícola que este modelo obteve em todos os países onde se implantou (Índia, Tailândia, México, Brasil etc.).

O objetivo deste trabalho é verificar até que ponto as tecnologias oriundas da revolução verde foram efetivamente adotadas na África Subsaariana e, nos casos em que foram adotadas, se tiveram sucesso em melhorar a renda e a produtividade da agricultura.

Para este fim o trabalho faz primeiramente um breve resumo do estado das artes da revolução verde na África mostrando os países que avançaram mais no sentido de utilizar fertilizantes químicos para gerar aumentos de produtividade. No terceiro capítulo se faz uma discussão sobre as características do processo de intensificação num caso em particular, Moçambique. Finalmente com base nos micro dados do Tratado de Inquérito Agrícola (TIA) se testa um modelo econométrico de MQO que visa avaliar os determinantes da renda agrícola, e em particular do uso de fertilizantes químicos.

\section{Revolução verde no contexto africano}

A revolução verde não entrou firmemente em África. Neste continente o uso de insumos agrícolas é ainda bastante reduzido.

Os agricultores africanos usam em média $9 \mathrm{~kg}$ de fertilizantes por hectare de terra arável em relação a $100 \mathrm{~kg} / \mathrm{h}$ no sul da Ásia, 135 no Sudeste Asiático e 73 na América Latina (CRAWFORD et al., 2006). Enquanto a produção agrícola e a produtividade subiram até $300 \%$ na Ásia e na América Latina durante as últimas quatro décadas (GUANZIROLI, 2010), na África essas variáveis estagnaram-se, resultando em uma dependência crescente de grãos importados, baixa produção e produtividade, e um aumento do número de pessoas subnutridas. ${ }^{3}$

A produtividade da maioria das culturas não apresenta na África uma melhora significativa desde a década de 1970, em grande parte como resultado do declínio da fertilidade do solo. Juntamente com o uso limitado de fertilizantes, contribuíram também para o baixo rendimento: a falta de acesso ao crédito, a extrema divisão da terra e o clima desfavorável.

Os solos, sem uso apropriado de técnicas agrícolas, foram profundamente erodidos e empobrecidos ao longo de séculos de agricultura minifundiária (um hectare em média de área cultivada por família). A fertilidade natural dos solos se desgastou e atualmente os solos carecem de nutrientes para dar lugar a uma produção maior. Práticas tradicionais de manter a fertilidade através do uso de sistemas de pousios (shifting cultivation ou roça e queima) já não são mais viáveis.

Com menos terra disponível para a produção e mais gente para alimentar, a pressão para aumentar a produtividade tornou-se muito forte. Nos anos 80 o debate relacionado à política de subsídios dos fertilizantes aumentou em intensidade, focando na capacidade dos governos para financiar e gerenciar de forma eficiente uma política que permitisse esse aumento de consumo.

Alguns países africanos, como Quênia, Tanzânia, Malaui, Ruanda e Zâmbia têm seguido, entre os anos 60 e os anos 80, programas de subvenção "universais" em grande escala para adoção de fertilizantes (DORWARD, 2009). Estes progra-

3. Segundo o Global Food Outlook (Instituto de Pesquisa da Política Alimentar em Washington), embora se perceba uma melhora na alimentação da população mundial, a situação tenderá a piorar na África subsariana, com o número de crianças subnutridas a aumentar 18 por cento, atingindo os 39 milhões. 
Figura 1. Correlação estatística entre uso de fertilizantes e produtividade agrícola. África

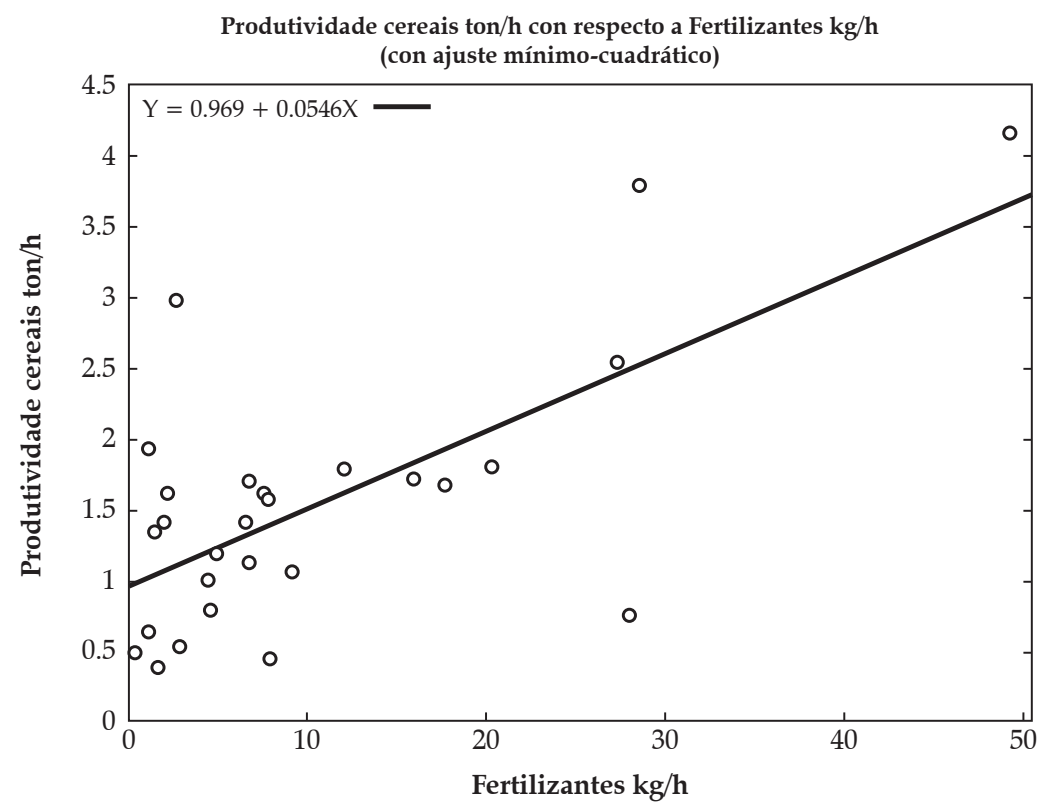

Fonte: Elaboração própria com base nos dados de FAO STATA.

mas se caracterizaram pelo controle estatal na distribuição dos insumos, que chegam aos produtores a preços subsidiados ou com crédito fortemente subsidiado. As experiências no âmbito destes programas foram variadas. Em alguns casos os programas conseguiram aumentar o uso de insumos ocasionando aumento da produtividade agrícola.

No entanto, os programas receberam fortes críticas pelos seguintes motivos: a) por serem caros, ${ }^{4}$ b) porque os subsídios tenderam a beneficiar agricultores relativamente abastados e melhor conectados e c) porque os avanços na produtividade agrícola eram dependentes de apoio continuado do governo. Além disso, os programas de subvenção de fertilizante eram propensos a ineficiências resultantes dos altos custos administrativos, do monopólio governamental e da manipulação política (BANFUL, 2010b).

Como parte do processo de ajustamento estrutural dos anos 80 e 90, os programas de subsídios agrícolas foram desmantelados e os mercados foram liberalizados, o que acarretou menor utilização de insumos e queda na produtividade agrícola (CRAWFORD et al., 2006).

4. Em média U\$ 200 milhões por ano, equivalente a 2,5\% do PIB dos países ou $10 \%$ dos seus orçamentos anuais.
Após um período de liberalização dos mercados agrícolas, novos programas de subsídio começaram a emergir em diversos países africanos. $\mathrm{O}$ Governo de Malaui, em 1998, abriu o caminho do retorno aos subsídios em grande escala, quando começou a distribuir fertilizantes sem custo para os agricultores ${ }^{5}$ (BANFUL, 2010b). Outros países, tais como Nigéria, Zâmbia, Tanzânia, Quênia, Gana seguiram logo o exemplo de Malaui.

Em 2006, a Nigéria hospedou o Summit de fertilizantes da África sob os auspícios da União Africana (AU), no âmbito da nova parceria para o desenvolvimento africano (NEPAD). Desse summit saiu a "Declaração de Abuja para a Revolução Verde Africana", em que os estados membros do AU se comprometeram a ajustar até 2015 o uso de fertilizantes a uma média de $50 \mathrm{~kg} / \mathrm{ha}$. Para isso adotaram um plano de ação que incluía o subsídio para melhorar o acesso aos fertilizantes para agricultores de pequeno porte.

Em função dessas políticas, alguns países notabilizaram-se por conseguirem aumentar a produtividade agrícola, como pode se observar na Figura 1.

5. O custo para o governo foi de U\$ 150 milhões anuais. Ver Tabela 2. 
Tabela 1. Produtividade de cereais e uso de fertilizantes. Países africanos

\begin{tabular}{ccc}
\hline \multirow{2}{*}{ País } & \multicolumn{2}{c}{ Valor médio 2008/2012 } \\
\cline { 2 - 3 } África do Sul & Produtividade ton $/ \mathrm{h}$ & Fertilizantes $\mathrm{kg} / \mathrm{h}$ \\
Malaui & 3,2 & 49,2 \\
Madagascar & 3,0 & 28,5 \\
Zâmbia & 2,5 & 2,7 \\
Ruanda & 1,9 & 27,3 \\
Gana & 1,8 & 1,1 \\
Gabão & 1,8 & 20,3 \\
Costa do Marfim & 1,7 & 12,1 \\
Camarões & 1,7 & 15,9 \\
Etiópia & 1,7 & 6,7 \\
Mali & 1,6 & 17,7 \\
Uganda & 1,6 & 7,6 \\
Algéria & 1,6 & 2,1 \\
Nigéria & 1,4 & 7,8 \\
Benin & 1,4 & 2,1 \\
Burundi & 1,3 & 6,6 \\
Senegal & 1,2 & 1,6 \\
Gâmbia & 1,1 & 4,9 \\
Burkina Faso & 1,1 & 6,8 \\
Moçambique & 1,0 & 9,1 \\
Congo & 0,8 & 4,4 \\
Zimbawe & 0,8 & 4,6 \\
Angola & 0,6 & 28 \\
Eritréia & 0,5 & 1,1 \\
Niger & 0,4 & 2,8 \\
Sudam & 0,4 & 1,6 \\
Namíbia & 0,3 & \\
\hline & &
\end{tabular}

Fonte: Elaboração própria com dados do Banco Mundial.

Na Tabela 1, mostram-se os países que compuseram a amostra.

Cabe destacar, dentre esses países, a experiência de Malaui que, com um programa baseado em tecnologias modernas como fertilizantes e sementes híbridas, contribuiu para que a produtividade e a produção do país fosse triplicada num curto intervalo de tempo (2006 a 2009), permitindo também ao país diminuir sua dependência de produtos importados, exportarem algum excedente, diminuir a pobreza rural e melhorar as variáveis macroeconômicas.

Por se tratar de um programa universal, este programa foi caro em relação a uma opção que foi calculada para Moçambique, conhecida como PIPP (Programa Integrado de Produção e Produtividade) ${ }^{6}$. O programa proposto para Moçambique diferentemente do programa do Malaui, focaliza num segmento específico de 145.000 produtores comerciais que tem capacidade de produzir grandes volumes (acima de 10 toneladas de cereais) e de ter um impacto mais eficiente na produção em função de sua experiência comprovada na agricultura.

Por esse motivo, a relação custo/benefício do PIPP de Moçambique é superior a de Malaui. Em Malaui foi necessário gastar em torno de U\$ 248 milhões por ano para aumentar a produção de milho do país ao nível atual de 2 milhões

6. Programa Desenvolvido pelo autor junto ao International Growth Centre (IGC) e à London School of Economics (LSE) em 2011, mas que ainda não foi implementado. 
de toneladas (acima do nível de 1,225 milhão de toneladas de milho que tinham anteriormente). Em Moçambique, se seguir o PIPP, com um custo de U\$ 45 milhões anuais, poder-se-ia aumentar a produção em 1.200 .000 toneladas de cereais. Veja-se a Tabela 2.

O programa do Malaui custou U\$ 124 por cada tonelada a mais produzida, enquanto que o de Moçambique custaria U\$ 37,5 por tonelada produzida, ou seja, quase quatro vezes menos. Portanto, trata-se de um programa que, por focalizar num alvo menor e mais produtivo, potencializa os recursos de forma mais eficiente.

Em Malaui, assim como na Tanzânia, Ruanda e Zâmbia, se fez basicamente uma doação massiva de fertilizantes e sementes (o pagamento dos vouchers foi simbólico) a um número relativamente grande de produtores pobres, enquanto que em Moçambique se daria crédito reembolsável a um número pequeno de produtores emergentes (145.000) que, no futuro, poderão se integrar positivamente nos mercados de crédito e de fatores em geral. O programa de Moçambique se enquadra na nova geração de programas conhecidos como "Programas Inteligentes (smarts) de Subsídio" que buscam evitar os problemas típicos dos subsídios universais. Para serem "inteligentes", os programas do subsídio devem aderir a um número de princípios, que podem ser resumidos da seguinte forma (MINDE et al., 2008):

- Focalização: Se o objetivo do governo for o de promover um maior crescimento econômico dever-se-ia focar em agricultores emergentes de tamanho médio. O restante do público, os pequenos agricultores, são mais vulneráveis, e afetados por falhas de mercado, tais como restrições de crédito e vulnerabilidade aos riscos de colheitas. Tais agricultores carecem de tecnologia, escala de operação, ativos produtivos e recursos financeiros para pagar, inclusive, por empréstimos subsidiados.

- Canais Privados de Comercialização: Dever-se-iam promover programas que utilizem as redes privadas existentes de distribuição dos insumos, evitando os sistemas controlados pelo Estado. Isto aumentará a probabilidade do programa ter um impacto sustentado após sua terminação.

- Estratégia de saída: Os programas de subvenção inteligente elaboram estratégias de saída críveis colocando um limite de tempo no suporte, para reduzir os riscos de que o programa seja "sequestrado" por interesses políticos (DORWARD, 2009). Por outro lado, na medida em que as partes interessadas esperam que o apoio continue indefinidamente, os incentivos para obter seus insumos via mercado diminuem.

Um programa de subvenções inteligente pretende apenas dar o "pontapé inicial" para o posterior uso do sistema de mercado na compra de insumos agrícolas. Se o programa ajudar os pequenos produtores a acumular ativos produtivos e financeiros, com alguns anos de colheitas excedentes, os agricultores podem ser capazes de comprar, após o término do programa, seus insumos "a preço cheio".

Tabela 2. Relação custo-benefício dos programas comparados

\begin{tabular}{lccccccc}
\hline Programa & $\begin{array}{c}\text { Produção de } \\
\text { milho antes do } \\
\text { programa }\end{array}$ & $\begin{array}{c}\mathbf{N}^{\circ} \text { Produtores } \\
\text { beneficiados }\end{array}$ & $\begin{array}{c}\text { Custo anual do } \\
\text { programa }\end{array}$ & $\begin{array}{c}\text { Acréscimo } \\
\text { produtivo }\end{array}$ & $\begin{array}{c}\text { Custo/Bene- } \\
\text { fício }\end{array}$ & $\begin{array}{c}\text { Valor } \\
\text { aplicado por } \\
\text { produtor }\end{array}$ \\
\cline { 2 - 8 } & Tonelada & $N^{\circ}$ & $U \$$ & Tonelada & $U \$ /$ ton & $U \$ / N^{\circ}$ \\
\hline Malaui-FISP & 1.225 .000 & 1.500 .000 & 248.000 .000 & 2.000 .000 & 124,0 & 165 \\
Moçambique-PIPP & 1.700 .000 & 145.000 & $45.000 .000 *$ & 1.200 .000 & 37,5 & 333 \\
\hline
\end{tabular}

Fonte: PIPP (2011). 


\section{Intensificação da produtividade agrícola com uso de técnicas modernas em Moçambique}

Em Moçambique, os diversos programas de incentivo a modernização agrícola da década de 2000 a 2010, como o PROAGRI (Programa Nacional de Desenvolvimento Agrário) e o PARPA (Plano de Ação para a Redução da Pobreza Absoluta),não foram capazes de promover aumentos significativos de produtividade, como mostra a Tabela 3.

No atual cenário em que decorre a produção agrícola, caracterizado pelo baixo uso de insumos agrícolas, a produtividade em Moçambique oscila entre 1/5 e 1/2 da produtividade média mundial, conforme ilustra a Tabela 3 .

Nota-se também que a baixa produtividade agrícola em Moçambique resulta de práticas de cultivo tradicionais. Muitas parcelas ainda são cultivadas recorrendo intensivamente ao trabalho braçal e utensílios manuais, com uma utilização mínima de sementes melhoradas ( $10 \%$ no caso do milho, 1,8\% no caso do arroz), de insumos químicos (4-5\%) e tração animal (11,3\%) (TIA (Tratado de Inquérito Agrícola, 2008).
Ainda mais agravante é o fato que a adoção de insumos modernos vem decrescendo ao longo do tempo como mostra a Tabela 4.

Embora o número de agricultores que usam fertilizantes tenha tido um pequeno aumento (7,9\%), a aplicação de pesticidas caiu em $44,1 \%$ e a irrigação caiu $19,3 \%$, combinado com a diminuição de 10,3\% no número de agricultores que tiveram acesso ao crédito rural.

Segundo Cunguara et al. (2012), em resposta à alta dos preços de alimentos no mercado mundial nos períodos mais recentes (2008-2011) teria havido expansão da área cultivada e maior uso de tração animal, mas sem nenhum aumento significativo na proporção de agregados familiares que usam fertilizantes químicos.

Segundo Cunguara et al. (2012)

\begin{abstract}
Os pequenos produtores em todas as áreas, exceto em Tetê, continuam a usar pouco fertilizante químico, quer devido a constrangimentos financeiros/crédito, quer devido ao acesso limitado aos revendedores de insumos. Sair da atual situação de uma virtual ausência de uso de fertilizantes químicos é um grande desafio para Moçambique, que vai exigir que
\end{abstract}

Tabela 3. Produtividade agrícola de Moçambique comparada com a mundial

\begin{tabular}{lcccc}
\hline Produto & $\begin{array}{c}\text { Produção } \\
\text { (ton) }\end{array}$ & $\begin{array}{c}\text { Área } \\
\text { (ha) }\end{array}$ & $\begin{array}{c}\text { Produtividade } \\
\text { (ton/ha) }\end{array}$ & $\begin{array}{c}\text { Produtividade Mundial } \\
\text { (ton/ha) }\end{array}$ \\
\hline Milho & 2.178 .842 & 1.812 .717 & 1,2 & 5,1 \\
Arroz & 271.402 & 238.778 & 1,1 & 4,3 \\
Mapira & 409.745 & 670.096 & 0,6 & 1,5 \\
Mexoeira & 51.602 & 113.642 & 0,5 & 0,9 \\
Amendoim & 157.685 & 372.964 & 0,4 & 1,6 \\
Feijões* & 263.771 & 543.324 & 0,5 & 0,8 \\
\hline
\end{tabular}

${ }^{*}$ Inclui todos os tipos de feijão.

Fonte: Aviso Prévio Minag (Ministério de Agricultura de Moçambique) e FAO STAT 2008.

Tabela 4. Percentual de estabelecimentos agrícolas que usam insumos modernos

\begin{tabular}{lccccccc}
\hline \multicolumn{1}{c}{ Descrição da Variável } & $\mathbf{2 0 0 2}$ & $\mathbf{2 0 0 3}$ & $\mathbf{2 0 0 5}$ & $\mathbf{2 0 0 6}$ & $\mathbf{2 0 0 7}$ & $\mathbf{2 0 0 8}$ & $\begin{array}{c}\text { Variação } \\
\mathbf{2 0 0 2 / 2 0 0 8}\end{array}$ \\
\hline Uso de Fertilizantes químicos & 3,8 & 2,6 & 3,9 & 4,7 & 4,1 & 4,1 & 7,9 \\
Uso de Pesticidas & 6,8 & 5,3 & 5,6 & 5,5 & 4,2 & 3,8 & $-44,1$ \\
Uso de Irrigação & 10,9 & 6,1 & 6,0 & 8,4 & 9,9 & 8,8 & $-19,3$ \\
Beneficiários de Crédito rural & & 2,9 & 3,5 & 2,9 & 4,7 & 2,6 & $-10,3$ \\
\hline
\end{tabular}

Fonte: Adaptado de Cunguara et al. (2012). 
fazedores de políticas resolvam os constrangimentos do sector privado para o desenvolvimento do mercado de insumos" (p. 3).

Existe, no entanto, uma parcela de produtores rurais que fazem uso de insumos modernos, como fertilizantes, pesticidas e sementes melhoradas. Embora esse setor encontre-se limitado a algumas regiões como Tête (CUNGUARA, 2012), percebe-se que, de forma geral, os agricultores que usam tais insumos são os que pertencem aos grupos de rendas mais elevadas no meio rural (quinto quintil). $\mathrm{Na}$ tabela abaixo se divide o uso de insumos por tipo de agricultor.

A correlação evidente entre os dados de renda e uso de insumos modernos não implica em nenhum tipo de causalidade. Entretanto, a elevada propensão de agricultores mais ricos a usar fertilizantes sugere que os agricultores mais pobres estão sujeitos a restrições orçamentárias.

Um simples modelo (variante de Ghatak e Jiang, 2002) com agricultores homogêneos e uma distribuição desigual de riqueza é capaz de mostrar que por serem restritos ao mercado de insumos, agricultores mais pobres não são aptos a maximizar sua função de produção na forma irrestrita, ao contrário dos mais ricos. Assim, adicionando crédito no modelo corta-se a persistência na pobreza, uma vez que agricultores mais pobres conseguirão utilizar fertilizantes e com isso, maximizar sua função de produção irrestritamente (o que gera maior lucro em uma função de produção bem comportada). Ou seja, embora a correlação não permita afirmar que um aumento no uso de insumos gera ascendência de quintil de renda, ela sugere que se o aumento de recursos for incentivado (via crédito, por exemplo) poderá haver aumentos de renda decorrente do aumento de produtividade gerado pelos insumos modernos.

Dados de Kelly e Cunguara de 2011 mostram que em média um produtor que usa fertilizantes químicos pode obter $166,8 \mathrm{~kg}$ per capita de milho enquanto que, sem fertilizantes, a produtividade se reduz a metade: $82,5 \mathrm{~kg}$ per capita. De todas as variáveis testadas (associação a organização social, extensão rural, tração animal), a dos fertilizantes foi a que teve maior impacto na produtividade.

Os autores concluem que a adoção de tecnologias melhoradas pode ter um efeito considerável nas rendas rurais, sempre e quando outros recursos também estejam disponíveis, tais como mão-de-obra, irrigação e tecnologias de conservação do meio ambiente.

Infelizmente, a escassez de financiamento rural tem dificultado a adoção dessas tecnologias por grupos mais numerosos de agricultores, o que se agravou recentemente em função dos substanciais aumentos de preço que tiveram os fertilizantes químicos (BENFICA, 2012)

Moçambique está entre os países com menor acesso a financiamento (incluindo todos os tipos de créditos rurais ou não rurais- comércio, indústria, serviços) como pode se observar na Tabela 6 .

Tabela 5. Percentual de explorações que usam insumos modernos por quintil de renda

\begin{tabular}{lccc}
\hline \multicolumn{1}{c}{ Quintil de Renda } & Uso de fertilizantes químicos & Uso de Pesticidas & Uso de Sementes melhoradas \\
\hline $1^{\text {o }}$ Quintil (mais pobre) & 0,75 & 1,0 & 8,20 \\
$2^{\text {o }}$ Quintil & 1,42 & 2,0 & 8,21 \\
$3^{\text {o }}$ Quintil & 2,63 & 3,0 & 9,29 \\
$4^{\text {o }}$ Quintil & 7,37 & 5,0 & 11.43 \\
$5^{\text {o }}$ Quintil (mais rico) & 10,25 & 5,0 & 12,74 \\
Total & 4,0 & 3,0 & 9,74 \\
\hline
\end{tabular}

Fonte: Adaptado de Cunguara, Mabiso e Hanlon (2011), com base na TIA 2008. 
Tabela 6. Percentual do crédito em relação ao PIB de países selecionados

\begin{tabular}{lcccccccccc}
\hline \multicolumn{1}{c}{ País } & $\mathbf{2 0 0 1}$ & $\mathbf{2 0 0 2}$ & $\mathbf{2 0 0 3}$ & $\mathbf{2 0 0 4}$ & $\mathbf{2 0 0 5}$ & $\mathbf{2 0 0 6}$ & $\mathbf{2 0 0 7}$ & $\mathbf{2 0 0 8}$ & $\mathbf{2 0 0 9}$ & $\mathbf{2 0 1 0}$ \\
\hline Moçambique & $\mathbf{9 , 1 6}$ & $\mathbf{1 2 , 2 2}$ & $\mathbf{1 0 , 2 5}$ & $\mathbf{8 , 1 4}$ & 8,30 & 8,08 & 10,06 & 13,95 & 22,32 & 24,07 \\
Brasil & $\mathbf{7 2 , 4 9}$ & $\mathbf{7 4 , 4 9}$ & $\mathbf{7 4 , 0 2}$ & $\mathbf{7 2 , 6 1}$ & $\mathbf{7 4 , 4 8}$ & $\mathbf{8 6 , 5 9}$ & 92,24 & 96,91 & 97,48 & 97,81 \\
Malawi & 15,79 & 15,41 & 16,01 & 16,04 & 16,63 & 14,14 & 16,61 & 27,45 & 32,04 & \\
Tanzânia & 8,46 & 8,86 & 7,30 & 7,45 & 11,56 & 11,30 & 13,52 & 17,03 & 18,15 & 20,92 \\
Alemanha & 144 & 142,4 & 140,7 & 137,8 & 136,1 & 131 & 124,5 & 126,3 & 131,8 & 130,8 \\
Namíbia & 43,46 & 42,15 & 46,50 & 49,60 & 55,59 & 52,56 & 48,47 & 43,16 & 44,71 & 48,43 \\
África do Sul & 184,34 & 159,82 & 163,12 & 169,62 & 178,49 & 192,93 & 195,34 & 172,92 & 184,39 & 182,32 \\
Quênia & 37,55 & 40,34 & 39,81 & 40,22 & 38,40 & 37,98 & 37,34 & 40,52 & 44,81 & 52,34 \\
Cabo Verde & 68,10 & 72,38 & 72,80 & 72,19 & 70,36 & 74,94 & 73,24 & 78,29 & 78,75 & 76,88 \\
Vietnam & 39,73 & 44,79 & 51,80 & 61,93 & 71,22 & 75,38 & 96,19 & 94,53 & 123,01 & 135,79 \\
Bolívia & 60,55 & 61,12 & 58,10 & 52,95 & 71,27 & 57,47 & 53,51 & 48,36 & 49,51 & 49,03 \\
\hline
\end{tabular}

Fonte: World Development Report (2011).

\section{Determinantes de renda na agricultura de Moçambique}

Tendo em vista que o uso de fertilizantes e outros insumos são importantes no processo de geração de renda decidiu-se por estimar sua importância relativa.

Usando informações da TIA de 2002 e 2005 formou-se um painel que permite estimar os determinantes do valor da produção do agregado familiar (AF). Como demonstrado na equação 1 , uma estimativa por MQO geraria viés de variável omitida, visto que a habilidade do agricultor e qualidade dos fatores de produção (capital, terra, trabalho e insumos) provavelmente influencia a utilização ótima dos mesmos.

$$
\begin{aligned}
& \ln (\text { valor da produção })_{i, t} \\
& =\mathrm{b}_{0}+\mathrm{b}_{1} \text { Trabalho }_{\mathrm{i}, \mathrm{t}}+\mathrm{b}_{2} \text { Capital }_{\mathrm{i}, \mathrm{t}} \\
& +b_{3} \text { Terra Utilizada } a_{i, t} \\
& +b_{4} \text { Insumos }_{i, t}+b_{5} \text { Habilidade }_{i, t} \\
& +b_{6} \text { Qualidade dos fatores de produção }{ }_{i, t} \\
& +u_{i, t}
\end{aligned}
$$

Na equação 1, supõe se que o valor da produção do agregado familiar i no período $t$ depende da utilização, no mesmo período, de quatro fatores de produção: Trabalho, Capital, Terra e Insumos; assim como da qualidade dos mesmos. Os coeficientes $\beta^{\prime}$ são interpretados como o retorno financeiro sobre o empenho em quantidade e qualidade dos fatores. $\mathrm{O}$ termo $\mathrm{u}_{\mathrm{i}, \mathrm{t}}$ é constituído por choques exógenos (como perdas por fatores climáticos, queimadas ou animais) de média zero. Visto que fatores climáticos são comuns em uma mesma região, pode-se ter correlação entre os choques de um mesmo distrito. Assim, para fazer testes de hipótese confiáveis podem-se usar clusters. Entretanto, o maior problema de estimativa vem do fato que habilidade e qualidade não são observáveis.

Desta forma, opta-se por estimar os retornos financeiros da utilização dos fatores de produção via uma equação de primeira diferença ${ }^{7}$. Assim, como se observa na equação 2 , considerando que a habilidade do agricultor e a qualidade dos fatores de produção (principalmente qualidade da terra) não mude nesse período de três anos, o problema de variável omitida é resolvido.

$$
\begin{aligned}
& D \ln (\text { valor da produção) } \\
& =b_{1} \text { D Trabalho }_{i}+b_{2} \text { D Capital }_{i} \\
& +b_{3} \text { D Terra Utilizada } a_{i} \\
& +\mathrm{b}_{4} \mathrm{D} \text { Insumos } \mathrm{s}_{\mathrm{i}}+\mathrm{Du}_{\mathrm{i}}
\end{aligned}
$$

Na Tabela 7 são mostradas estatísticas descritivas para as variáveis incluídas. A variável de valor da produção foi construída multiplicando a quantidade já colhida e a colheita esperada pelo preço (observado ou esperado) de 2002. Como

7. Conclusões semelhantes foram obtidas por Mather, 2012. 
Tabela 7. Estatísticas descritivas

\begin{tabular}{|c|c|c|c|c|}
\hline Variável & Ano & Média & Variação & $\begin{array}{l}\text { Desvio } \\
\text { Padrão }\end{array}$ \\
\hline \multirow{2}{*}{ Valor da Produção (Mt) } & 2002 & 3.135 & \multirow{2}{*}{$8,9 \%$} & 3.953 \\
\hline & 2005 & 3.413 & & 6.573 \\
\hline \multirow{2}{*}{ Trabalhadores Temporários } & 2002 & 1,8 & \multirow{2}{*}{$24,8 \%$} & 9,6 \\
\hline & 2005 & 2,3 & & 7,8 \\
\hline \multirow{2}{*}{ Trabalhadores Permanentes } & 2002 & 0,0 & \multirow{2}{*}{$77,9 \%$} & 0,3 \\
\hline & 2005 & 0,1 & & 0,6 \\
\hline \multirow{2}{*}{ Utiliza tração animal? } & 2002 & $13 \%$ & \multirow{2}{*}{$-22,0 \%$} & $34 \%$ \\
\hline & 2005 & $10 \%$ & & $31 \%$ \\
\hline \multirow{2}{*}{ Área Total (Ha) } & 2002 & 1,74 & \multirow{2}{*}{$16,8 \%$} & 1,9 \\
\hline & 2005 & 2,04 & & 1,9 \\
\hline \multirow{2}{*}{ Área em Culturas Temporárias(Ha) } & 2002 & 1,44 & \multirow{2}{*}{$29,2 \%$} & 1,2 \\
\hline & 2005 & 1,86 & & 1,8 \\
\hline \multirow{2}{*}{ Área em Culturas Permanentes(Ha) } & 2002 & 0,17 & \multirow{2}{*}{$-69,1 \%$} & 0,4 \\
\hline & 2005 & 0,05 & & 0,4 \\
\hline \multirow{2}{*}{ Área Irrigada (Ha) } & 2002 & 0,09 & \multirow{2}{*}{$-41,2 \%$} & 0,4 \\
\hline & 2005 & 0,05 & & 0,3 \\
\hline \multirow{2}{*}{ Valor de Fertilizantes (Mt de 2002) } & 2002 & 30,2 & \multirow{2}{*}{$17,2 \%$} & 371 \\
\hline & 2005 & 35,4 & & 271 \\
\hline \multirow{2}{*}{ Valor de Pesticidas (Mt de 2002) } & 2002 & 14,7 & \multirow{2}{*}{$1,5 \%$} & 133 \\
\hline & 2005 & 14,9 & & 124 \\
\hline \multirow{2}{*}{ Educação } & 2002 & 3,3 & \multirow{2}{*}{$24,2 \%$} & 2,5 \\
\hline & 2005 & 4,1 & & 2,7 \\
\hline \multirow{2}{*}{ Perdeu parte da produção? } & 2002 & $72 \%$ & \multirow{2}{*}{$33,3 \%$} & $45 \%$ \\
\hline & 2005 & $96 \%$ & & $20 \%$ \\
\hline
\end{tabular}

* 3.269 observações por ano.

Fonte: Elaboração própria com base nos micro dados da TIA (Tratado de Inquérito Agrícola) de 2002 e 2005. INE. Instituto Nacional de Estatística.

cada agregado familiar pode produzir diversas culturas, somou-se o valor destas colheitas ${ }^{8}$.

Observa-se que houve um crescimento de 8,9\% no valor da produção médio durante o período de três anos (entretanto, a variância aumentou muito).

Também, houve maior contratação de funcionários permanentes (crescimento de 77,9\%) assim como de temporários (crescimento de 24,8\%). Por outro lado, o número de AF's que utiliza tração animal diminuiu em 3 pontos percentuais. Esta medida é dúbia, uma vez que tração animal representa um avanço tecnológico em relação ao uso de força braçal, mas é um atraso tecnológico

8. As culturas consideradas foram: milho, arroz, mapira, mexoeira, amendoim, feijão,mandioca, batata doce, algodão,tabaco, sisal, cha, girassol, gergelim, soja, paprica e gengibre. obs: não se incluiu batata reno e cana de açúcar por falta de dados. se comparado à utilização de tratores. De qualquer forma, está é a única medida palpável fornecida pela TIA para representar estoque de capital.

A área total dos $\mathrm{AF}^{\prime}$ 's entrevistados aumentou em $16,8 \%$. Como se trata de uma comparação entre os mesmos agregados, é possível que esse valor seja devido a erro de medida (o aumento médio é de apenas 0,3 hectares). Contudo, mudanças mais importantes para esta análise são a de um aumento na área utilizada por culturas temporárias (29,2\% ou 0,42 hectares) em prol de uma redução na área utilizada por culturas permanentes $(-69,1 \%$ ou 0,12 hectares). Também se observou uma redução de hectares irrigados (medida construída a partir da dummy "possui irrigação?" por área da machamba).

Os valores de fertilizantes e pesticidas de 2005 foram deflacionados (IPC). Assim, também se observou um aumento nestes valores - $17,2 \%$ para 
Tabela 8. Utilização de fertilizantes e pesticidas (valores)

\begin{tabular}{|c|c|c|c|c|c|}
\hline & \multirow{2}{*}{ Ano } & Fertilizantes & \multirow{2}{*}{ Variação } & Pesticidas & \multirow{2}{*}{ Variação } \\
\hline & & (Valor médio, MZ\$ de 2002) & & (Valor médio, $M Z \$$ de 2002) & \\
\hline \multirow{2}{*}{ Utilizou } & 2002 & 708 & \multirow{2}{*}{$16,0 \%$} & 208 & \multirow{2}{*}{$9,6 \%$} \\
\hline & 2005 & 821 & & 228 & \\
\hline
\end{tabular}

Fonte: Elaboração própria com base nos micro dados da TIA (Tratado de Inquérito Agrícola) de 2002 e 2005. INE. Instituto Nacional de Estatística.

Tabela 9. Utilização de fertilizantes e pesticidas (composição)

\begin{tabular}{lcccc}
\hline & $\begin{array}{c}\text { Fertilizantes } \\
\text { (no de AF's) }\end{array}$ & $\%$ & $\begin{array}{c}\text { Pesticidas } \\
\text { (no de AF's) }\end{array}$ & $\%$ \\
\hline Não utilizou & 3053 & $93 \%$ & 2926 & $90 \%$ \\
Utilizou só em 2002 & 79 & $2,4 \%$ & 145 & $4,4 \%$ \\
Utilizou só em 2005 & 81 & $2,5 \%$ & 127 & $3,9 \%$ \\
Utilizou nos dois anos & 56 & $1,7 \%$ & 71 & $2,2 \%$ \\
Total de AF's & 3269 & $100 \%$ & 3269 & $100 \%$ \\
\hline
\end{tabular}

Fonte: Elaboração própria com base nos micro dados da TIA (Tratado de Inquérito Agrícola) de 2002 e 2005. INE. Instituto Nacional de Estatística.

fertilizantes e 1,5\% para pesticidas. Entretanto, tais valores subestimam o valor médio de quem utiliza fertilizante. A Tabela 8 expõe melhor esse fato. Nela, observa-se que o valor médio de uso de fertilizante cresce de 708 para 821 meticais $^{9}$ de $2002(16 \%)$, valores substancialmente superiores aos apresentados na Tabela 5. A análise é semelhante para o uso de pesticidas. A Tabela 7 mostra porque isso ocorre. Apenas 7\% dos AF's utilizaram fertilizantes em algum momento, enquanto um pouco mais de $10 \%$ utilizaram pesticidas.

Voltando à Tabela 7 , dados de educação devem ser interpretados como o maior nível de educação reportado por membros do agregado familiar (maiores de 10 anos), em uma escala de 0 a 13 anos de estudo. Percebe-se que embora haja uma evolução, a escolaridade é muito baixa nos AF's estudados (cresceu de 3,3 para 4,1 anos de estudo).

A variável "Perdeu parte da produção?" conglomera AF's que perderam parte da produção por seca, chuva, animais, queimadas ou outros. Os dados informam que a vasta maioria dos $\mathrm{AF}^{\prime}$ 's tiveram alguma dificuldade no ano de 2005 $(96 \%)$. Por fim, incluiu-se uma variável de dias de seca na província, retirada de Mather (2002).

9. Metical (Mt): nome da moeda moçambicana. Um dólar (U\$) equivale a aproximadamente Mt 30.
A Tabela 10 a seguir contém as estimações por $\mathrm{MQO}^{10}$ e Primeira Diferença como segue das equações (1) e (2). Vale notar que variáveis como valor da produção, área, fertilizantes e pesticidas estão em log. Não se utilizou a ponderação da amostra nas estimações. Entretanto, isso não deveria afetar demasiadamente os coeficientes estimados. Como mencionado, utilizou-se cluster para distritos, corrigindo o erro padrão.

A coluna 1 apresenta as estimativas da regressão por MQO. Vemos que um aumento de $10 \%$ da área de culturas temporárias aumenta o valor da produção em 3,1\%. Trabalho temporário e permanente, tração animal, fertilizantes e pesticidas também apresentam retornos positivos e estatisticamente diferentes de zero. Já as dummies ${ }^{11}$ de "perdeu parte da produção", dias de seca e dummy de ano apresentam coeficientes negativos.

Embora os sinais dos coeficientes estimados estejam de acordo com a hipótese, este modelo deve estar viesado, como vimos. Assim, as colunas de 2 a 5 são comparáveis e não apresentam

10. Método de Mínimos Quadrados Ordinários.

11. As variáveis dummy são variáveis qualitativas, também conhecidas como indicativas, binárias, categóricas e dicotômicas. Só podem assumir os valores 0 e 1 , indicando respectivamente ausência ou presença de una qualidade ou atributo. 
Tabela 10. Regressões em painel. Variável dependente: log do valor da produção (preços de 2002)

\begin{tabular}{|c|c|c|c|c|c|}
\hline \multirow{2}{*}{ Variáveis } & (1) & $(2)$ & (3) & $(4)$ & (5) \\
\hline & $M Q O$ & $1^{\underline{a}}$ Dif & $1^{\underline{a}}$ Dif & $1^{a}$ Dif & $1^{\underline{a}}$ Dif \\
\hline \multirow{2}{*}{ Ln(Área de culturas Temporárias) } & $0.314^{* * *}$ & $0.217^{* * *}$ & $0.221^{* * *}$ & $0.221^{* * *}$ & $0.221^{* * *}$ \\
\hline & $(0.0360)$ & $(0.0421)$ & $(0.0420)$ & $(0.0419)$ & $(0.0419)$ \\
\hline \multirow{2}{*}{ Ln(Área de culturas Permanentes) } & $0.0191^{*}$ & 0.00446 & 0.00902 & 0.00902 & 0.00902 \\
\hline & $(0.0105)$ & $(0.0152)$ & $(0.0150)$ & $(0.0149)$ & $(0.0150)$ \\
\hline \multirow{2}{*}{ Ln(Área irrigada) } & $0.0333^{* * *}$ & 0.0153 & 0.0192 & -0.0246 & 0.0190 \\
\hline & $(0.0125)$ & $(0.0167)$ & $(0.0164)$ & $(0.0268)$ & $(0.0163)$ \\
\hline \multirow{2}{*}{ Trabalho Temporário } & $0.0162^{* * *}$ & $0.00956^{* * *}$ & $0.00936^{* * *}$ & $0.00942^{* * *}$ & $0.00937^{* * *}$ \\
\hline & $(0.00315)$ & $(0.00350)$ & $(0.00353)$ & $(0.00355)$ & $(0.00354)$ \\
\hline \multirow{2}{*}{ Trabalho Permanente } & $0.116^{* * *}$ & 0.0727 & 0.0712 & 0.0680 & 0.0719 \\
\hline & $(0.0440)$ & $(0.0633)$ & $(0.0634)$ & $(0.0620)$ & $(0.0646)$ \\
\hline \multirow{2}{*}{ Utiliza tração animal? } & $0.202^{*}$ & 0.0420 & 0.0633 & 0.0662 & 0.0635 \\
\hline & $(0.114)$ & $(0.145)$ & $(0.146)$ & $(0.146)$ & $(0.146)$ \\
\hline \multirow{2}{*}{ Ln(Fertilizantes) } & $0.150^{* * *}$ & $0.0998^{* * *}$ & $0.0999^{* * *}$ & $0.103^{* * *}$ & $0.110^{* *}$ \\
\hline & $(0.0149)$ & $(0.0290)$ & $(0.0299)$ & $(0.0294)$ & $(0.0452)$ \\
\hline \multirow{2}{*}{ Ln(Pesticidas) } & $0.0429^{* * *}$ & 0.0360 & 0.0329 & 0.0327 & 0.0333 \\
\hline & $(0.0151)$ & $(0.0306)$ & $(0.0315)$ & $(0.0314)$ & $(0.0309)$ \\
\hline \multirow{2}{*}{ Perdeu parte da produção? } & $-0.104^{*}$ & -0.0638 & -0.0370 & -0.0376 & -0.0366 \\
\hline & $(0.0561)$ & $(0.0891)$ & $(0.0823)$ & $(0.0822)$ & $(0.0822)$ \\
\hline \multirow{2}{*}{ Dummy de ano } & $-0.0796^{* * *}$ & $-0.103^{* * *}$ & $-0.0699^{*}$ & $-0.0685^{*}$ & $-0.0699^{*}$ \\
\hline & $(0.0203)$ & $(0.0247)$ & $(0.0371)$ & $(0.0370)$ & $(0.0371)$ \\
\hline \multirow{2}{*}{ Dias de seca } & $-0.00364^{* *}$ & & -0.00695 & -0.00167 & -0.00694 \\
\hline & $(0.00180)$ & & $(0.00593)$ & $(0.00642)$ & $(0.00594)$ \\
\hline \multirow{2}{*}{ Ln(Área irrigada)*Dias de seca } & & & & $0.000813^{* *}$ & \\
\hline & & & & $(0.000393)$ & \\
\hline \multirow{2}{*}{ Ln(Fertilizantes)* Dias de seca } & & & & & -0.000298 \\
\hline & & & & & $(0.00136)$ \\
\hline № de Observações & 6,538 & 6,538 & 6,538 & 6,538 & 6,538 \\
\hline R-quadrado & 0.157 & 0.675 & 0.676 & 0.677 & 0.676 \\
\hline
\end{tabular}

Erros padrões corrigidos por cluster em parênteses. ${ }^{*} \mathrm{p}<0.1 ;{ }^{* *} \mathrm{p}<0.05 ;{ }^{* * *} \mathrm{p}<0.01$.

Fonte: Elaboração própria com base nos micro dados da TIA (Tratado de Inquérito Agrícola) de 2002 e 2005. INE. Instituto Nacional de Estatística.

tal viés. Observa-se que nas diferentes especificações o retorno de um aumento em área de culturas temporárias é positivo, em torno de 2,2\% (para um aumento de 10\%). Já o retorno no aumento de área de culturas permanentes é estatisticamente igual a zero.

Embora o coeficiente de área irrigada também seja igual a zero, na coluna 4 vemos que a interação deste com dias de seca tem coeficiente positivo. Ou seja, em áreas mais secas, maior irrigação gera maior retorno.

Trabalho temporário apresenta retornos positivos, embora muito baixos. Já trabalho permanente tem coeficientes nulos. A utilização de tração animal é outra que apresentava coeficiente positivo e significativo no modelo de MQO e não tem significância nos modelos de primeira diferença.

Os coeficientes para valor utilizado de Fertilizantes são repetidamente positivos. Embora o retorno não seja muito alto (um aumento de $10 \%$ tem retorno sobre a produção de $1 \%$ ) é importante observar que este é a metade do retorno de aumento na área de culturas temporárias, além de ser maior do que o estimado em estudos anteriores (MATHER, 2012). A utilização de pesticidas não apresentou coeficiente significativamente diferente de zero.

As dummies de "perdeu parte da produção" e "dias de seca" não apresentam valores significa- 
tivamente diferentes de zero em nenhuma destas especificações. Por fim, a dummy de ano apresenta valor negativo, indicando que o valor da produção foi menor em 2005 como um todo.

Outro problema deve ser levado em consideração. Mesmo com o modelo de primeira diferença, deve-se entender que a decisão do agricultor de quanto produzir, quanta terra, trabalho e insumos utiliza é endógena, podendo depender de inúmeros fatores não observáveis.

Em suma, os dados analisados das TIA $2002 \mathrm{e}$ 2005 permitem concluir que há um retorno maior na produção para agricultores que usam fertilizantes e que tal retorno é relativamente superior aos estimados em estudos anteriores (MATHER, 2012).

\section{Conclusões}

Nas décadas de 1980 e 1990, o Banco Mundial e vários países doadores conseguiram que os Governos de África eliminassem suas políticas de subsídios aos fertilizantes. Isso gerou na década de 1990 até início dos anos 2000 um forte déficit na produção de alimentos. No Malaui, durante a campanha eleitoral de 2004, o partido no poder (PPD-Partido Popular Democrático) e o bloco de oposição comprometeram-se a reintroduzir um programa de subsídios ao uso de fertilizantes químicos de caráter universal.

Uma primeira lição da aplicação destes programas revela que as respostas dos agricultores são rápidas ao estímulo da oferta. Os agricultores da África estão bem cientes do potencial que tem os fertilizantes e as sementes híbridas em aumentar a produção. Uma vez eliminado o principal obstáculo a produção, que está dado pelo custo proibitivo dos insumos, surgem condições para explorar o potencial produtivo da agricultura africana.

O trabalho econométrico apresentado revela que o uso de fertilizantes químicos tem um impacto considerável na produtividade e renda agrícola dos agricultores moçambicanos.

Dados secundários mostravam também que os agricultores de renda superior usavam maior quantidade de fertilizantes e tinham maior acesso ao crédito.

O trabalho permite supor que adicionando crédito no modelo corta-se a persistência na pobreza, uma vez que agricultores mais pobres conseguirão utilizar fertilizantes e com isso, maximizar sua função de produção irrestritamente (o que gera maior lucro em uma função de produção bem comportada) estável.

A adoção de tecnologias melhoradas, entretanto, pode ter um efeito considerável nas rendas rurais, sempre e quando outros recursos também estejam disponíveis, tais como mão de obra, irrigação e tecnologias de conservação do meio ambiente.

A nova geração de políticas agrícolas, chamada de "smart subsidies" substitui a universalização pela focalização o que permite obter benefícios crescentes com custos reduzidos do programa. Ao invés de conceber uma sociedade rural homogênea de "agricultores de pequena escala", a política proposta caracteriza mais claramente as diferentes categorias de agricultores e as relações entre eles e o conjunto da economia.

No entanto um programa de subsídios aos insumos - mesmo que inclua distribuidores privados e que se destine a agricultores que, sem ele, não teriam acesso a sementes e fertilizantes - só responde aos objetivos de curto prazo. Um programa desse tipo deve ser apenas um dos ingredientes de uma política destinada a desenvolver a agricultura de maneira sustentável, que deve focar no investimento em infra- estrutura e pesquisa e à criação de um ambiente favorável aos operadores privados.

\section{Referências bibliográficas}

AFRICAN UNION. Policy Brief On Agricultural Finance In Africa. Journal of Development Economics, v. 69, n. 2002, p. 205-226, 2012.

BANFUL AFUA, B. Constraints to Fertilizer Use in Nigeria Insights from Agricultural Extension Service. IFPRI Discussion Paper 01010, jul. 2010. 
BUAINAIN, A. M. e GUANZIROLI, C. E. Trajetória Recente da Política Agrícola Brasileira. Projeto FAO/ INCRA. UTF/BRA/036/BRA.Brasília-DF, 1998.

CANTORE, N. The Crop Intensification Program in Rwanda: asustainability analysis. UNDP UNEP, 2012.

CRAWFORD ERIC, W. T. S. e JAYNE, V. A. K. Alternative Approaches for Promoting Fertilizer Use in Africa. Agriculture and Rural Development Discussion Paper 22 The International Bank for Reconstruction and Development / The World Bank, 2009.

CUNGUARA, B., MUDENA, J., MATHER, D. e TSCHIRLEY, D. Mudanças no Padrão de Cultivo e Uso de Insumos pelos Pequenos Produtores no Centro e Norte de Moçambique, 2008/2011. Flash. No 60 P. Revista da Direção de Economia do MINAG, 2012.

, JOÃO MUDEMA, D. M. e DAVID, T. Changes in Smallholder Cropping and Input Use in Central and Northern Mozambique, 2008/2011. 15 nov. 2012 flash N. 60E.

, MABISO e HANLON. Trends in food security in Rural Mozambique, 1996-2008. Manuscript submitted to Food Policy, WB, 2011.

DORWARD, A. C. P. Getting agricultural moving: role of the state in increasing staple food crop productivity with special reference to coordination, input subsidies, credit and price stabilization. Draft no published, 2008.

et al. Disaggregated impact of credit reform in Malawi. Paper presented at the First Meeting of the OECD Global Forum on Agriculture: Designing and Implementing Pro-Poor Agricultural Policies, Paris, December 10th and 11th 2003. Centre for Development and Poverty Reduction, Imperial College London.

et al. Towards 'smart' subsidies in agriculture?Lessons from recent experience in Malawi. Natural Resource Perspectives 1, 16 set. 2008. ODI.

., EPHRAIM, C. e JAYNE, T. S. The Malawi Agricultural Inputs Subsidy Program, 2005/6 to 2008/9, 2009.
EICHER, C. e STAATZ, J. Agricultural Development in The Third World. John Hopkins, UK, 1984.

FAO/ONU. Organização das Nações Unidas para Alimentação e Agricultura. FAO STAT.

GUANZIROLI, C. E. Agronegocio y Agricultura Familiar En Brasil: Políticas Agrícolas y Agrarias Que Dieron Suporte En Los Últimos Treinta Años. Conferencia CIDE, 10 e 11 de novembro de 2010, México D.F.

JORGENSON, D. The Development of a Dual Economy. The Economic Journal, jun. 1961.

KELLY, B. e CUNGUARA, B. The Impact of the PARPA II in promoting the agricultural sector in Mozambique, 2012.

LEWIS, W. A. Economic development with unlimited supplies of labour. The Manchester School, v. 22, issue 2, p. 139-191, maio 1954.

MATHER, D. Determinants of Crop Income in Rural Mozambique, 2002-2005. Direção de Economia, Ministério de Agricultura de Moçambique, jan. 2012. Ressearch Report 71.E

MINDE ISAAC, T. S. et al. Promoting Fertilizer Use in Africa: Current Issues and Empirical Evidence from Malawi, Zambia, and Kenya. ReSAKSS Working Paper, n. 13, nov. 2008.

PIPP. Programa Integrado de Produção e Produtividade para Moçambique. Draft no published.IGC/LSE, 2011.

ROSTOW, W. W. The Stages of Economic Growth: A Non-Communist Manifesto. Cambridge: Cambridge University Press, 1960.

SCHULTZ, T. W. Transforming Traditional Agriculture, reprinted in (1983). Chicago: University of Chicago Press, 1964.

TIA. Tratado de Inquérito Agrícola. MINAG, 2008.

WIGGINS, S. Success Stories from African Agriculture: What are theKey Elements of Success? DS Bulletin, v. 36, n. 2, Institute of Development Studies, jun. 2005.

WORLD BANK. World Development Report, 2011 